\title{
EX ORDIUM
}

\section{SHARED LEARNING AND SUSTAINABILITY COMMIT- MENT. THE GREEN OFFICE OF UNIVERSITY OF BOLOGNA di Gabriella Calvano}

The commitment of universities for sustainable development requires students' involvement and participation, as they are the major actors in the necessary process of change in our complex and interconnected world. Taking the case of the Green Office of the University of Bologna into consideration, this study analyses how students participation can not only stimulate the debate about the issue of sustainability at universities, but can also lead to possible solutions.

L'impegno delle università per lo sviluppo sostenibile implica il coinvolgimento e la partecipazione degli studenti, protagonisti indiscussi di un cambiamento necessario per vivere in un mondo complesso e interconnesso. Il contributo analizza, attraverso il case study del Green Office dell'Università di Bologna, un esempio di come la partecipazione degli studenti può favorire la riflessione sui problemi di insostenibilità di un ateneo ma anche l'individuazione comune di possibili soluzioni.

\section{Introduction. University and sustainability: a relationship for reciprocal development}

Recently, education for sustainable development has gathered momentum both at an international level (both as a result of the Decade of Education for UNESCO Sustainable Development and as a consequence of the subscription of 193 UN member countries of the 2030 Agenda and the Sustainable Development Goals), and at a national level (e.g. of the National Plan of Educa- 
tion for Sustainable Development in July 2017). Such attention inevitably involves higher education.

In fact, for many years now, specialized literature and international institutions interested in education for sustainable development (United Nations, UNESCO, UNEP etc.) have been pointing out the key role and the potential that Universities have in the creation of a more equal, right and sustainable world (UNESCO, 2014). This potential is not only expressed in the educational goal of Universities (committed to providing knowledge, skills and competences to future professionals, teachers, politicians and decision makers) but also in their commitment in research and third mission that, despite having a global vision, can only be rooted in a specific territory where common solutions can be identified and processes of participation and awareness can be triggered off to start the transition to a sustainable development. This is one of the reasons why research and innovations in alternative energy, waste, the use (and reuse) of water as well as the study of migratory processes and corporate social responsibility, food and the circular economy can only be shared and co-constructed. Only in this way the research for possible solutions can be meaningful for both university and local community (Trencher, Bai, Evans, Yarime \& McCormick, 2014a).

A university committed to sustainable development should have its main focus on education (Calvano, 2017). The main issue is to guarantee interdisciplinary and transversal educational processes (UNESCO, 2017) that do not simply result in the design of specific study courses on sustainability, but also implement the use of pedagogical practices in order to promote a set of skills suitable to live in a complex and interconnected world, capable of generating that effective thought that comes from the living experience and constantly refers to it because reality is an instrument of continuous comparison and test of one's own thinking (Mortari, 2008).

The goals of a sustainable development need the cooperation and participation of all the university community and all the stakeholders, whose resistance could represent a significant obstacle in the university's growth of a sustainability culture. 
Several studies have shown that multistakeholder partnerships can improve the sustainable education processes through learning by doing, leading to several advantages especially for the students (Brundiers \& Wiek, 2013; Brundiers, Wiek \& Redman, 2010; Wiek, Xiong, Brunders \& von de Leeuw, 2014). However, very few researches focused on the potential social impact of students' participation.

Although the co-creation of knowledge, instruments and social changes is a conceptual framework (Mauser et al., 2013; Trencher et al., 2014a) to understand universities' tendency to collaborate with stakeholders for sustainability (Trencher, Yarime, McCormick, Doll \& Kraines, 2014b), where knowledge is not an end in itself but a trigger for social changes (Trencher et al., 2014a; van Veen, Bunders \& Regeer, 2013), there are still very few occasion of co-creation for students. This is a serious obstacle for them to understand the complex challenges of sustainability in real contexts (Jiusto, McCauley \& Stephens, 2013).

\section{Students' participation: a key element for a sustainability committed University}

The role of universities in sustainability is widely acknowledged, however still few studies focus on the stakeholders' (and students in particular) perception of their role in the process (Emanuel \& Adams, 2011; Wright, 2010). Emphasising this element could make students more involved as stakeholders in universities' initiatives on sustainability as well as make them a source for feedback on the efficacy of universities' actual commitment on that matter. University students are, indeed, fundamental agents in the transition toward sustainable development.

Universities should have a sound and visible commitment to sustainability and the education to sustainability. This could lead students to adopt sustainable values, attitudes and behaviours and to promote a new idea of future. In an uncertain and rapidly changing world, higher education has a significant role in empowering students to be active and responsible citizen. However, as Butt, Moore \& Avery (2014) showed in their research, the ef- 
fective involvement of students in universities decisions on the matter is still very little. Universities do not consider students as key agents in their own community both in developing sustainable practices and in the organisational and political support related to those practices. Sustainability can become, in the future, a key element of competitiveness among students. Universities are expected to foster suitable sustainability programs and standards, acting as models for future generations.

Students, working with teachers and administrative staff, can really contribute to universities institutional development gaining at the same time new skills. Universities, on their side can benefit of useful inputs and ideas from the students. Collaboration becomes an instrument to foster change.

The Green Office model, which will be presented in the following part, provides a learning environment where students (with teachers, administrative staff, and external experts) face several knowledge and sources of information, asking questions and guessing possible answers on their university's "unsustainability" issues. Discussing about actual problems connected with urban issues and needs, allows students to discuss and to commit to finding suitable solution of identified sustainability issues.

3. The Green Office model and the importance of students'participation: the case study of UNIBO

Born in 2010 at the Maastricht University, the Green Office «is a platform that empowers the wider university community to act on sustainability. It also realises its own ideas to embed sustainability in education, research and operations..

This model spread, through rootAbility (http://rootAbility.com), in six European countries, counting twenty four Green Offices, including the University of Bologna.

The University of Bologna started its path towards sustainability in 2009. The "Terracini in transition" project and the related Green Office, with structural measures launched at Terracini de- 
partment (where the School of Environmental, Chemistry and Management Engineer is) promote, through ad hoc learning projects, the creation of a living lab where students, teachers and administrative staff: share knowledge, experiences, propose new ideas; promote, realise and share practical projects and spread good practices related to sustainability. In specific situations of sharing and discussion, students develop a "strong" critical thinking, seen as the acquisition of «refined logic and argumentative skills $[\ldots]$ based on the constant discussion on relevant social, economic, political issues» (Mortari, 2008, p. 38) for their own university and for the city of Bologna as well.

The main aim of the Green Office UNIBO is to promote and support the transition of the University of Bologna toward a more sustainable future, enhancing the ideas, talents and abilities of university students, proposing itself as a reference point for the education and research for sustainable development within the University and within the local community.

The project aims to promote active participation of students as well as creating collaboration among the different actors and institutions, creating several impacts:

- social: promotion of sustainability culture in both the University of Bologna and the local territory; support the changing of every day practices, creation and strengthen of several collaboration within the University (between students, teachers and administrative staff) and with external collaborators; promotion of new collaboration networks between the University of Bologna and other universities in Italy and internationally, joining the Green Office network and through rootAbility; students acquisition of skills and knowledge, useful to become part of the labour market; promoting the active participation of students and their empowerment through a bottom-up approach;

- environmental: reduction of food waste, CO2 emissions, energy; promotion of sustainable mobility; increase of separate waste collection; 
- economic: job opportunities for students; increase of University economic savings through programmes for energy saving, food management, waste management.

For these reasons, the UNIBO Green Office proposes to promote and generate small daily changes in the lifestyles of those who are part of the university community, with the hope that these changes can be brought outside the University with a considerable impact on the life (professional or otherwise) of students, researchers, teachers and technical and administrative staff.

\section{Why participate? Opinions and motivations of the Green Office UNIBO students}

Through a semi-structured interview to thirteen students and technical and administrative staff of the University of Bologna involved in the project "Terracini in transition" it was possible to set up a phenomenological qualitative research, which allowed us to focus on:

- motivation that has prompted students to choose to do an additional formative experience that calls into question their own experiences and that also asks them to engage in political terms for the construction of the common good at university and at a citizen level, which is precisely the aim of the Green Office;

- perception about the potential that an experience like this can generate.

The interviews were conducted according to an informed protocol including questions not provided in advance to the interviewees to avoid "artificial" responses and attitudes. The interviews were digitally recorded and manually transcribed.

The collected interviews showed that the technicaladministrative staff (four people) participation in the Green Office by was fundamentally motivated by the possibility of giving a 
meaning to what was already done in professional terms. On the other hand, the students' motivation is very different: they decided to participate in the project to concretise what they have been studying or for personal interest or to learn to look at the university in a different way. The experience of the Green Office, in particular, can give «the possibility of working in collaboration with other people who have the same motivation [...] who believe in the same values [...] in the same principles» (F.L.), but also «to see the reality in a different way because we, as students, often do not feel like the university as ours. Instead the Terracini laboratories are the opportunity to see it as our home» (E.S.).

About the perceived potential of the "Terracini in transition" as project, no difference were detected between the administrative and technical staff and the students. In particular, the detected potential were:

- educational;

- create new relationships and strengthen the existing ones.

The educational potential is expressed in the creation of a greater awareness about the themes of environment and sustainability, making clear a particular attention to them:

Although in this decentralized venue there is the department of environmental engineering [...] the environmental component is strong [...] however, no one notices it, entering in this department. Instead, "Terracini in transition" makes clear a great evidence to these issues and therefore allows those who are interested to get in and collaborate. [...]. Moves consciences (F.L.).

The word "conscience" echoes in the words of S.P. «everyone should try to approach this reality to carry on a sustainable conscience ...universities should support this and students should be interested in these issues».

"Terracini in transition" is therefore conceived as a «connector of practices that can help everyone with examples of sustainable actions» (EF), but also as 
a great educational tool because it changes the point of view [...] is no longer the teacher who provides [...] let's say [...] the knowledge, concepts ... the solutions, but the solutions are designed together with the students [...] we become a community [...] useful to other communities(FC).

The participants in the project express another important potential of the Green Office: the creation and the strengthen of the relationships between people and between disciplines. As E.S. highlights very well:

I really like the interdisciplinarity [students of] management engineering mechanic engineering civil engineering realise that these aspects are not just for some of us, but for everyone. The Green Office also allows us to get to know each other outside our groups ... which is not a small thing ... as we are very sectorial and we know it. It is an opportunity to get to know each other and improve, which is always good.

\section{Conclusions}

Data showed that the students that took part in "Terracini in Transition" project have the widespread need to concrete commit themselves politically (starting from a significant experience such as the university one) about issues that can no longer be delayed such as sustainability and its thousands characterising aspects, as well as the awareness of how often the training received in the classrooms does not adequately allow the acquisition of those skills that make each student an actor and author of change, a true global citizen, politically conscious and committed.

The experience of the Green Office, therefore, in its focus on students involvement in the participation of the University of $\mathrm{Bo}$ logna sustainability policies and practices, can undoubtedly represent a model of a particular educational interest, that also strengthens the link with the territory in the awareness that the third mission, which fits well with the prospect of change (Formica, 2014). 
This questions universities to guarantee an adequate educational offer (Moore, 2005), and the impact that this and other university policies have in the short and medium run (Lozano, 2008).

It is fundament today to reconsider the way of doing education and training at all levels of the tertiary education system if we want to build a future really devoted to sustainable development.

\section{Bibliografia}

Brundiers K., \& Wiek A. (2013). Do we teach what we preach? An international comparison of problem- and project-based learning courses in sustainability. Sustainability, 8, 53-68.

Brundiers K., Wiek A., \& Redman C. (2010). Real-world learning opportunities in sustainability: from classroom into the real world. International Journal of Sustainability in Higher Education, 11, 308-324.

Butt L., Moore E., \& Avery G.G. (2014). The myth of the "green student": student involvement in Australian university sustainability programmes. Studies in Higher Education, 39(5), 786-804.

Calvano G. (2017). Educare per lo sviluppo sostenibile. L'impegno degli Atenei Italiani: esperienza in corso e buone pratiche. Roma: Aracne.

Emanuel R., \& Adams J. (2011). College students' perceptions of campus sustainability. International Journal of sustainability in Higher Education, 12(1), 79-92.

Formica C. (2014) (a cura di). Terza missione. Parametro di qualità del sistema universitario. Napoli: Giapeto Editore.

Jiusto S., McCauley S., \& Stephens J.C. (2013). Integrated Shared Action Learning into Higher Education for Sustainability. Joumnal of Sustainability education, http://www.jsedimensions.org/wordpress/wpcontent/uploads/2013/0 /Jiustoe-al-2013-Shared-Action-Learning-FINAL-1-PDF-Ready.pdf.

Lozano R. (2008). Envisioning sustainability three-dimensionally. Journal of Cleaner Production, 16(17), 1838-1846.

Mauser W., Klepper G., Rice M., Schmalzbauer B.S., Hackmann H., Leemans R., \& Moore H. (2013). Transdisciplinary global change research: the co-creation of knowledge for sustainability. Current Opinion in Environmental Sustainability, 5, 420-431.

Moore J. (2005). Seven recommendations for creating sustainability education at university level: a guide for change agents. International Journal of Sustainability in Higher Education, 6(4), 326-339. 
Mortari L. (2008). Educare alla cittadinanza partecipata. Milano: Bruno Mondadori.

Trencher G., Bai X., Evans J., Yarime M., \& McCormick K.B. (2014a). University partnership for co-designing and co-producing urban sustainability. Global Environmental Change, 28, 153-165.

Trencher G., Yarime M., McCormick K.B., Doll C.N.H. \& Kraines S.B. (2014b). Beyond the third mission: exploring the emerging university function of co-creation for sustainability. Science and Public Policy, 41(2), 151-179.

UNESCO (2014). Shaping the future we want. UN Decade of Education for SustainableDevelopment 2005-2014 Final Report, Paris. Available in: http://unesdoc.unesco.org/images/0023/002301/230171e.pdf [15 aprile 2018].

UNESCO (2017). Education for Sustainable Development. Leaning Objectives, http://unesdoc.unesco.org/images/0024/002474/247444e.pdf. [22 aprile 2018].

van Veen S., Bunders J., \& Regeer B. (2013). Mutual learning for knowledge co-creation about disability inclusive development: experiences with a community of practice. Knowledge Management for Development Journal, 9(2), 105-124.

Wiek A., Xiong A., Brunders K., \& von de Leeuw (2014). Integrating problem- and project-based learning into sustainability programs: a case study on the School of Sustainability in Arizona State University. International Journal of Sustainability in Higher Education, 15, 431-449.

Wright T. (2010). University president's conceptualization of sustainability in higher education. International Journal of Sustainability in Higher Education, 11(1), 61-73. 